\title{
Cervical Parameters and Preterm Labour
}

\author{
Dr Mohammad Othman \\ (Consultant and Assistant Professor, Department of Obstetrics and Gynecology, Faculty of Medicine, Al-Baha \\ University)
}

\begin{abstract}
Preterm birth is the most important cause of neonatal death and morbidity, with immense costs to families and health care systems. In spite of advances in obstetric care, thirteen million preterm birth occur annually worldwide. Preterm birth is multifactorial in origin, but in the last 20 years, infection has emerged as an important and frequent cause of preterm labour and birth. The most common pathway of infection into the uterus is the ascending route from the vagina.

This is an exploratory study to investigate if cervical immunology and morphology would better refine high-risk status for future clinical trials. The hypothesis is that a defective cervical barrier is a major cause of preterm labour. This hypothesis was assessed immunologically by using flow cytometry to quantify leucocytes subpopulation in the cervix, morphologically by cervical length and volume as assessed by $3 D$ ultrasound, and the cervical blood circulation was assessed by $3 D$ ultrasound with power Doppler in patients at high risk of preterm labour. Immunologically, the most prevalent cervical leukocyte was the macrophage. Macrophages and the rest of leukocyte types in general were fewer in high-risk patients than in normal pregnant controls, but this difference did not reach statistical significance. This could be due to the sample size. Alternatively, this could be due to the collection of the cervical samples very early in pregnancy. The influx of leukocytes is expected later in pregnancy or at the time of cervical ripening prior to labour. Morphologically, this study showed a significant association between cervical length and preterm labour, but not cervical volume. This could be due to the sample size or due to the difficulty of estimating cervical volume. In addition, there is increase in the vascularisation of the cervix in preterm labour patients and this could be due to the small sample size, difficulty of defining the cervix landmarks or premature remodeling of cervical architecture since all these women had previous histories of preterm labour.
\end{abstract}

Keywords: Preterm birth, Cervical Flow Cytometry, Cervical Length, Cervical Volume, 3D Ultrasound and Power Doppler, Macrophages, Prospective Observational Cohort.

\section{Background}

Preterm birth, defined as birth occurring after the gestational age of viability ( 23 weeks, 500 grams weight) and before 37 completed weeks (259 days) of pregnancy, is one of the most important problems in medicine today. Preterm birth is the single largest cause of mortality and morbidity for newborns. It accounts for $5 \%$ to $11 \%$ of births in the world but is responsible for $28 \%$ of all deaths within 28 days of birth and $50 \%$ of childhood neurological disabilities [1,2]. Other important adverse outcomes of preterm birth include respiratory distress syndrome, intraventricular haemorrhage, leukomalacia, necrotizing enterocolitis and prolonged hospitalisation [2]. Survivors can experience life-long complications including cerebral palsy, blindness and deafness $[1,2]$.

Psychologically, giving birth to a preterm infant is considered to be a stressful event for parents. Many studies have shown that mothers of these infants experience increased levels of stress in the neonatal period compared with mothers of term infants, and they are more likely to suffer from depression and anxiety at the time of hospital discharge [3]. There is also increased depressive symptoms among fathers of preterm infants during the neonatal intensive care unite stay [4]. It is assumed that increased parenting stress could interfere with the parent-child relationship during early childhood and consequently increase the risk for later behavioural problems $[3,5]$.

The direct and indirect costs of prematurity can be immense [2]. The lifetime costs per preterm birth (baby's birth weight less than 2500 grams) have been estimated at $£ 511,614[1,6]$.

The incidence of preterm deliveries in developed countries is $6 \%$ to $9 \%$, currently it is $7 \%$ in the UK affecting 21,000 babies each year in England. Preterm premature rupture of the membranes and spontaneous preterm labour accounts for approximately $80 \%$ of preterm deliveries; the remaining $20 \%$ are planned deliveries for maternal or fetal reasons (for example, eclampsia) [7].

In the last 20 years it has become clear that infection is an important cause of preterm labour and delivery leading to more than $50 \%$ of the all preterm deliveries world-wide [1, 8-14]. Infection has been recognised as an important and frequent mechanism of disease in preterm birth with a firm link to prematurity. The evidence that implicate infection as a cause of preterm labour and birth includes: 
- Administration of microbial products to pregnant animals results in preterm birth.

- Systematic maternal infection, for example, pyelonephritis, pneumonia or even Dental caries are associated with preterm labour.

- Subclinical intrauterine infections usually trigger preterm birth.

- Treatment of asymptomatic bacteriuria prevents preterm labour.

- Clinical infection is increased in the infant and the mother after preterm birth.

- $10-15 \%$ of amniotic fluid cultures from preterm labour patients are positive for microorganisms.

- Antibiotic treatment of intrauterine infections can prevent prematurity in experimental models of chorioamnionitis [15].

Since infection is frequently difficult to confirm, we often refer to women with positive amniotic culture, histological evidence of chorioamnionitis or elevated cytokines in the amniotic fluid as having a subclinical infection. In this context, the organisms involved may not be necessarily pathogenic; a change in vaginal flora may be enough to trigger the sequence of events leading to a preterm birth $[1,2,8,11,14,16-18]$.

The most common pathway for pathogens to cause preterm labour is the ascending route $[2,14]$ : several mechanisms contribute to this pathway. Pathogens produce proteolytic enzymes including different types of mucinases, sialidases, peptidase and protease. The presence of bacterial sialidases facilitates the attachment of bacteria to cervical mucus and the breakdown of mucin, while bacterial mucinases assist ascent into uterine tissues $[2,12,19]$. Other enzymes may act directly on cervical collagen leading to premature shortening and ripening cervix while also weakening the fetal membranes leading to preterm premature rupture of the membranes $[2,12,19]$.

Microorganisms stimulate maternal monocytes and macrophages resulting in the production of phospholipase $\mathrm{A}_{2}$. This is an enzyme that liberates arachidonic acid from the phospholipids of the membranes leading to the synthesis of prostaglandins $\mathrm{E}_{2}$ and $\mathrm{F} 2 \alpha$ by the placental membranes: prostaglandins are potent stimulator of uterine contractions [14, 20-27]. Similarly, protease toxins activate the decidua and fetal membranes to produce Cytokines such as Tumor Necrosis Factor (TNF), Interleukin (IL1 $\alpha$, IL1 $\beta$, IL6, IL8), and Granulocyte-Macrophage Colony Stimulating Factor (GM-CSF) [9, 12, 14, 20-22, 25-27]. The activation of a local inflammatory reaction leads to prostaglandin synthesis and release which subsequently stimulate uterine contractions [28-30]. Moreover, in infected foetuses, there is an increase in both fetal hypothalamic and placental production of corticotrophin releasing hormone leading to increase in fetal corticotrophin secretion, which in turn increases fetal adrenal cortisol production leading to increased production of prostaglandins [20, $25,28]$. When the fetus is infected, there is a high increase in the production of cytokines and marked decrease in the delivery time with a high chance of direct fetal tissue damage (e.g. fetal brain or lung) $[2,14,19,20,24$, $25,31]$.

During pregnancy the primary function of the uterine cervix is to remain closed in order to retain the baby within the uterus until fetal maturity and birth. A secondary function of the cervix is to prevent infection ascending from the vagina into the uterus. Prior to normal delivery at term, cervix shortens, softens and ripens (becomes more distensible), to facilitate cervical dilatation by myometrial contractions during labour. The cervix consists mainly of connective tissue, principally, collagen fibers in a proteoglycan ground substance. The interaction between these two substances gives the cervix its unique characteristics, where the collagen fibers resist pulling forces and the ground substance resists compressive forces [32].

Various methods have been used to try and detect cervical changes that predict preterm labour. These include manual vaginal examination, transabdominal ultrasound, and transvaginal ultrasound $[29,33]$. Of these modalities, measurements of cervical length using transvaginal ultrasound scanning appear to have the highest sensitivity, whereas transabdominal scanning was not predictive $[29,30]$. There is however, no clear cut gestation at which the test should be performed or what cervical length provides the best cut-off for a diagnostic test $[29,33]$.

\section{Rationale}

We have analysed observational data on 106 women with a past history of preterm labour and birth [34] in order to test the hypothesis that women with a past history of preterm labour and birth have a more marked inflammatory response in the cervical mucus. Strikingly, we found that in a subsequent pregnancy, women with a low macrophage count ( $<5 \%$ of cervical epithelial cells expressing CD14 antigen) before 20 weeks gestation were more likely to have recurrent preterm birth compared with women who had normal cervical macrophage count (Odds Ratio 4.9, 95\%CI 1.5 to 18.7; P 0.0037). This prompted us to develop a new model for ascending infection, that ascending infection occurs in the presence of a defective cervical barrier. 
Objective

\section{Methods And Materials}

To investigate to what extent a defective cervical barrier is a contributory factor to recurrent preterm labour.

\section{Hypothesis}

Patients at high risk of preterm labour will have lower number of cervical leukocytes in general and macrophages specifically. The lower the number of macrophages the less vascular the cervix would be, which would result in low readings on power Doppler indices.

\section{General methods}

This is a hospital prospective observational cohort (non-interventional study). Study was conducted in Liverpool Women's Hospital from October 2007 until October 2009. One of the aims of this study was to estimate the parameters for sample size calculations in further studies, therefore there was no formal prior sample size calculation. The plane was to recruit 50 cases and 50 parous controls. Inclusion criteria for cases included being between 13-17 weeks gestation and certain gestational age confirmed by ultrasound with history of at least one unexplained previous birth between 20 and 32 completed weeks (preterm birth was not caused by preeclampsia, pregnancy induced hypertension, Abruptio placenta, severe intrauterine growth retardation, intrauterine fetal death, hemophilia or any chronic systematic disease).

Cases were excluded if they were primigravida, has a history of cervical cerclage, history of cervical weakness (need for elective cervical suture at or before 16 weeks gestation), uterine congenital anomalies, drug addiction, younger than 18 years old, planned for antenatal care or delivery elsewhere, history of chronic systematic disease requiring treatment during pregnancy, fetal congenital anomalies and fetal death.

Controls were recruited from the general antenatal clinic as pregnant women between 13-17 weeks and certain gestational age confirmed by ultrasound. Exclusion criteria for controls were the same as cases added to that any history of previous preterm birth ( $<37$ weeks).

In the normal routine booking visit (12 - 18 weeks), all women with a history of previous preterm birth were assessed in the Preterm Labour Clinic. Routine investigations carried out following a booking ultrasound scan. At the end of this booking visit, women were informed about the study. Women who agree to take part were consented then had a cervical swab, Cytobrush swab of the external cervical os and 3D Trans-Vaginal Scan, Figure 1. Control group had routine investigations done in the first visit (12 - 18 weeks). At the end of this booking visit, women were informed about this study and if agreed to participate, they were consented then had vaginal and cervical swabs and 3D ultrasound done as above.

\section{Laboratory methods}

Using sterile speculum cervix visualized and cytobrush used to collect cervical cells. A cytobrush is a fine cervical cytobrush (Cervix-brush, Rovers Medical Devices, Oss, Netherlands) gently rotated twice 360 degrees in the cervical canal. Tip of the brush is separated and pushed into the sample bottle, which is kept cold all the time. The sample then processed and prepared for flow cytometry using different fluorescence labelled $\mathrm{CD}$ antigens, Table 1. In flow cytometry Fluorescence-activated cell sorting (FACS) was used. Because of the differences in the size and granularity, different cervical cells are plotted in different gates. Since cervical epithelial cells are very large cells, they are represented in the far end outside the scale of the forward scatter, which is the $\mathrm{X}$-axis on the dot plot. While the difference in intensity of granularity between the types, different layers and function of these cells causes them to be distributed in relation to, the side scatter on the Y-axis, Figure 1. FACS results are then analysed using WinMDI programme.

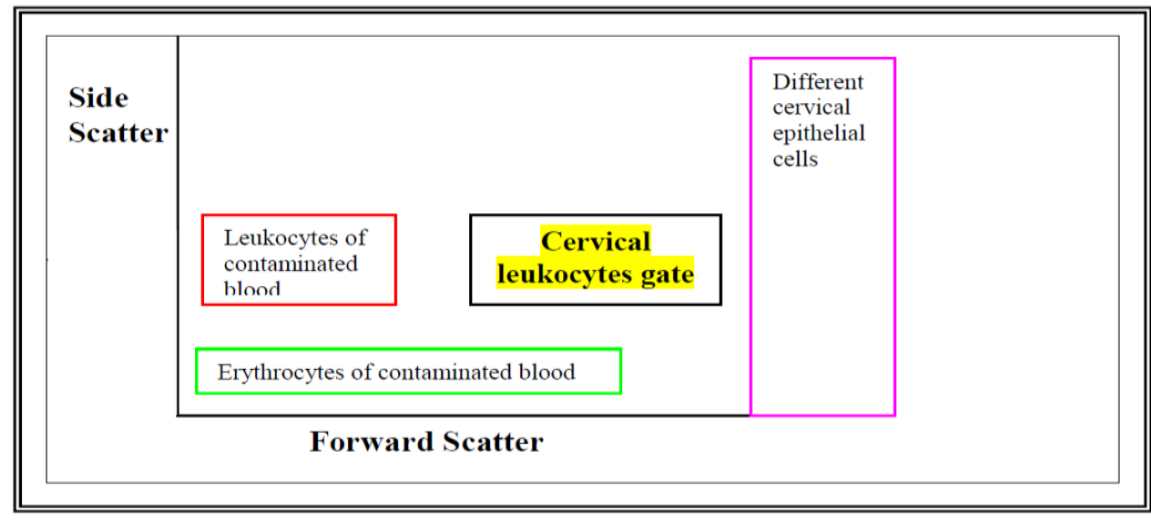

Figure 1: Schematic representation of the FAC's histogram and gate for cervical leukocytes 


\section{D ultrasound methods}

After collecting the cervical sample from the participants 3D ultrasound with power Doppler examination carried out using Voluson i machine with LOGIQ 9 transvaginal transducer, using Preset default and Gain 5. For Power Doppler settings were Quality low and PRF 0.6, while 3D ultrasound settings are Static, Max angle and Quality low, Figure 1. Ultrasound results were analysed using 4D view programme. Primary descriptive analysis used aiming to estimate the parameters for sample size calculations in further hypothesis testing studies. Standard parametric and nonparametric testing used to compare the results between high risk group and controls. Conventional level of statistical significance $(\mathrm{P}<0.05)$ used.

\section{Results}

89 participants were recruited, 50 controls and 39 patients. Demographically both groups were similar. The difference in the history of previous preterm birth was statistically significant but this is expected since patients were defined as having history of previous preterm birth while, this is an exclusion criteria in the controls, Table 1.

\begin{tabular}{|c|c|c|c|}
\hline & $\begin{array}{c}\text { Patients } \\
\mathbf{N = 3 9}\end{array}$ & $\begin{array}{c}\text { Controls } \\
\mathbf{N}=\mathbf{5 0}\end{array}$ & $\mathbf{P}$ \\
\hline $\begin{array}{c}\text { Age } \\
\text { median (range) }\end{array}$ & $31(20-39)$ & $29(19-39)$ & 0.366 \\
\hline $\begin{array}{c}\text { Smoking } \\
\%\end{array}$ & $23.08 \%$ & $22 \%$ & 0.904 \\
\hline $\begin{array}{c}\text { parity } \\
\text { median (range) }\end{array}$ & $1(1-6)$ & $1(1-3)$ & 0.166 \\
\hline $\begin{array}{c}\text { previous PTB } \\
\text { median (range) }\end{array}$ & $1(1-6)$ & $0(0)$ & 0.0001 \\
\hline $\begin{array}{c}\text { gestational age } \\
\text { median (range) }\end{array}$ & $15(13-16)$ & $15(13-16)$ & 0.405 \\
\hline
\end{tabular}

Table 1: Demographic properties of the participants

Of the 39 patients 22 delivered after $34+0$ completed weeks and 17 delivered before $34+0$ weeks. Of those delivered preterm, three delivered before $20+0$ completed weeks, one before $24+0$ completed weeks and thirteen before $28+0$ completed weeks, Figure 2 .

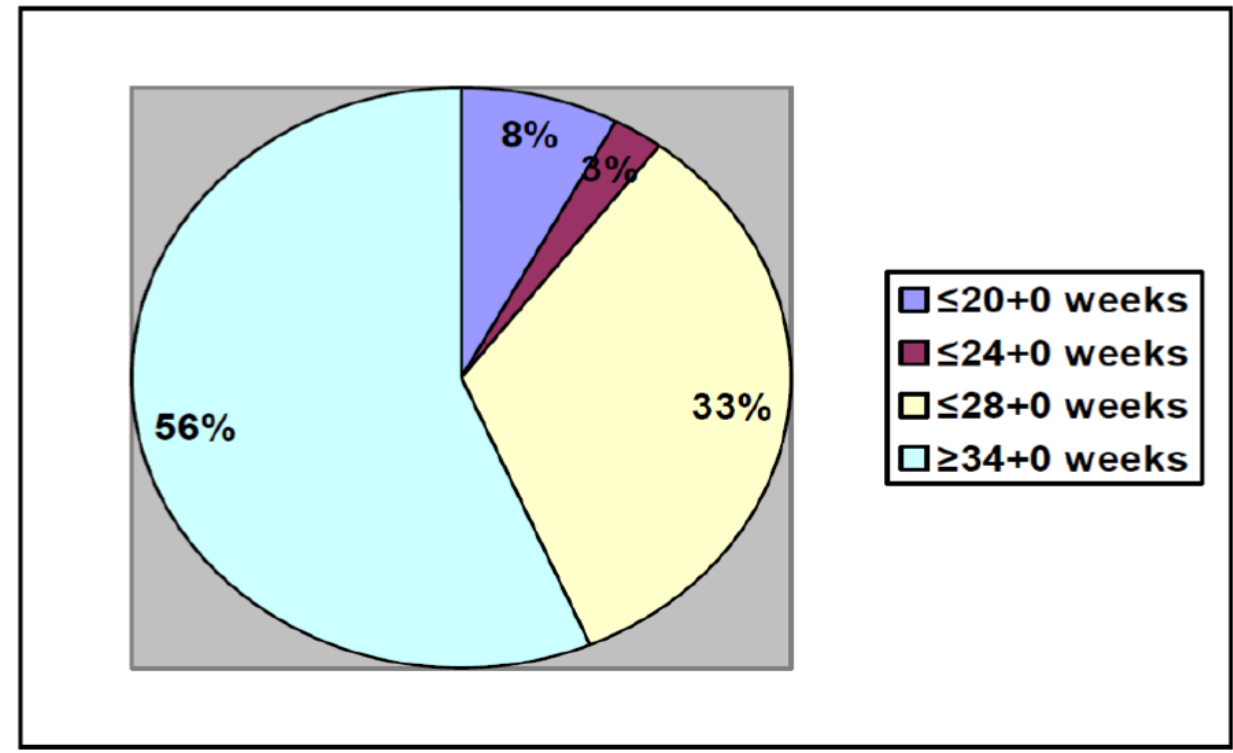

Figure 2: Patient's gestational age at delivery 
Only one patient underwent caesarean section (for history of previous caesarean section). Another patient developed pregnancy induced hypertension and on admission she complained of abdominal pain. She delivered within 4 hours of admission at $26+3$ weeks gestation.

Three babies delivered before $20+0$ weeks died within 30 minutes of delivery. One baby delivered before 24+0 weeks was admitted to the NICU, but unfortunately developed infection and died at the age of 2 weeks. The rest of the patient's babies were admitted to the NICU and later discharged in good condition.

All controls delivered after $34+0$ completed weeks of the pregnancy. Six controls underwent caesarean section. Three of those controls had a history of previous caesarean section. The other three had caesarean sections for antepartum haemorrhage, one for abruptio placentae and two for placenta praevia. Two sets of twins delivered vaginally. One at $36+4$ weeks, the other at $37+2$ weeks.

Of all babies delivered to controls, three babies were admitted to the NICU for meconium ingestion and discharged later in good condition. For the rest of the results, patients who delivered after completed 34+0 weeks of gestation were excluded from the analysis. The most common leukocytes present in both groups were macrophages. Leukocytes showed no difference between the two groups, Table 2.

\begin{tabular}{|c|c|c|c|}
\hline $\begin{array}{c}\text { Cell count } / \mathbf{1 0}^{4} \text { cells } \\
\text { median (range) }\end{array}$ & $\begin{array}{c}\text { PTB }<\mathbf{3 4 + 0} \\
\mathbf{N}=\mathbf{1 7}\end{array}$ & $\begin{array}{c}\text { Controls } \\
\mathbf{N = 5 0}\end{array}$ & $\mathbf{P}$ \\
\hline Macrophages & $14(1-21)$ & $16(1-53)$ & 0.16 \\
\hline Monocytes & $0(0-1)$ & $0(0-2)$ & 0.81 \\
\hline B cells & $0(0)$ & $0(0-2)$ & 0.41 \\
\hline T cells & $0(0-3)$ & $0(0-26)$ & 0.98 \\
\hline Granulocytes & $0(0-23)$ & $0(0-54)$ & 0.08 \\
\hline Dendritic cells & $0(0)$ & $0(0-21)$ & 0.32 \\
\hline
\end{tabular}

Table 2: Leukocytes results

Ultrasound results showed a statistically significant association between decrease in cervical length and preterm labour. On the other hand, a decrease in cervical volume was not associated with preterm labour, Table 3.

\begin{tabular}{|c|c|c|c|}
\hline $\begin{array}{c}\text { Cervix } \\
\text { mean (SD) }\end{array}$ & $\begin{array}{c}\text { PTB }<\mathbf{3 4 + 0} \\
\mathbf{N}=\mathbf{1 7}\end{array}$ & $\begin{array}{c}\text { Controls } \\
\mathbf{N}=\mathbf{5 0}\end{array}$ & $\mathbf{p}$ \\
\hline $\begin{array}{c}\text { Length } \\
\text { (mm) }\end{array}$ & $41.3(5.2)$ & $44.4(7.8)$ & 0.04 \\
\hline $\begin{array}{c}\text { Volume } \\
\text { (cm3) }\end{array}$ & $30.4(8.9)$ & $33.1(14.7)$ & 0.25 \\
\hline
\end{tabular}

Table 3: 3D Ultrasound results

Settings for the ultrasound examination found to be different from the agreed settings in two patients. Added to that, artifacts affected two other examinations. Consequently, power Doppler data were also affected. Those four patients were excluded from the analysis. For the controls, settings of the ultrasound examination found to be different from the agreed settings in thirteen controls. In the other hand, artifacts did not affect any of the controls examinations. Those thirteen controls were excluded from the analysis.

An increase in vascular index and vascular flow index were associated with preterm labour. The flow index did not show any significant difference between the two groups, Table 4. 


\begin{tabular}{|c|c|c|c|}
\hline $\begin{array}{c}\text { Doppler indices } \\
\text { median (SD) }\end{array}$ & $\begin{array}{c}\text { PTB <34+0 } \\
\mathbf{N}=\mathbf{1 3}\end{array}$ & $\begin{array}{c}\text { Controls } \\
\mathbf{N}=\mathbf{3 7}\end{array}$ & $\mathbf{p}$ \\
\hline $\begin{array}{c}\text { Vascular Index } \\
\text { (\%) }\end{array}$ & $31.3(8.7)$ & $15.5(9.6)$ & 0.0006 \\
\hline $\begin{array}{c}\text { Flow Index } \\
\text { (unit) }\end{array}$ & $36.1(2.6)$ & $35.2(2.9)$ & 0.61 \\
\hline $\begin{array}{c}\text { Vascular Flow } \\
\text { Index (unit) }\end{array}$ & $12(3.5)$ & $5.3(3.7)$ & 0.0009 \\
\hline
\end{tabular}

Table 4: 3D Ultrasound with Power Doppler results

No significant correlation was found between cervical macrophages and neither the 3D ultrasound parameters measured nor the 3D ultrasound with power Doppler indices measured, Figure 3.

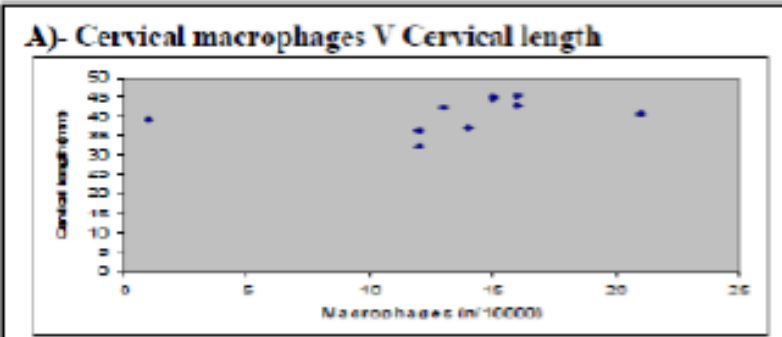

B)- Cervical macrophages V Cervical volume

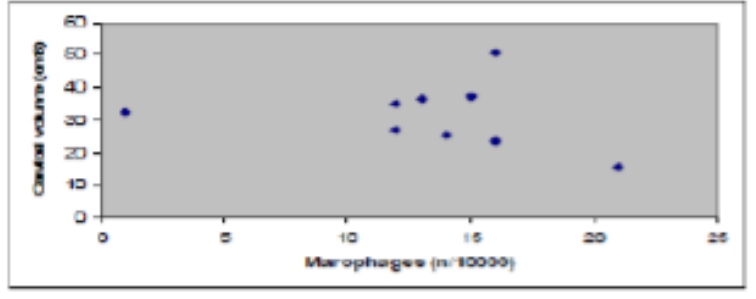

C)- Cervical macrophages V Cervical Vascular Index

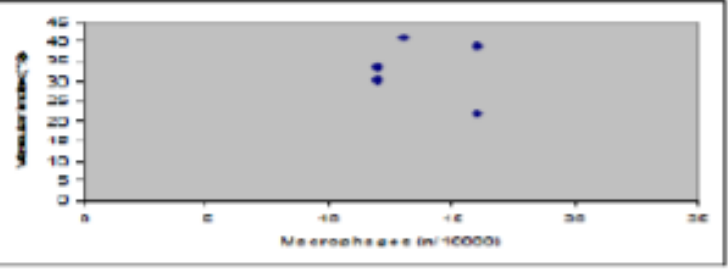

D)- Cervical macrophages V Cervical Flow index

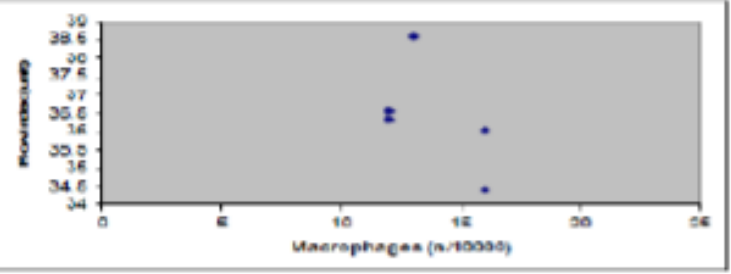

E)- Cervical macrophages V Cervical Vascular Flow indes

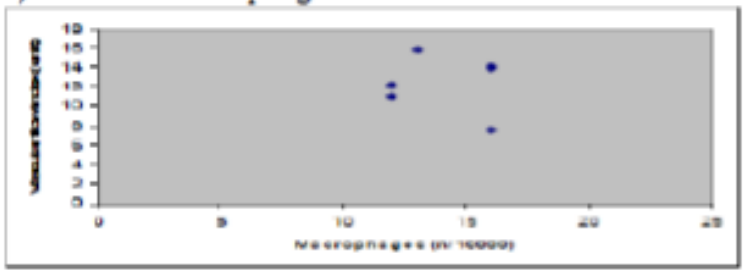

A) - No significant conelation was found between cervical macrophages and ccrvical length. Correlation coefficient $=$ 0.45 P 0.22

B)- No significant comelation found between cervica! macrophages and cervical volume. Correlation coefficient $=0.5 \mathrm{P} 0.36$

C)- No sienificant correlation found between cervica. macrophages and cervical vascular index. Correletion coefficient $=0.25$ P 0.59

D)- No significent corrclation found between cervical. macropheges and cervical flow index. Correlation coefficient 0.24 P 0.59

E)- No significant correlation found between cervica! macrophages and cervical vascular flow index. Conrelation coefficient -0.23 P 0.56

Figure 3: Macrophages, 3D Ultrasound parameters and Power Doppler indices correlations 


\section{Discussion}

Twin pregnancies were included in this study because there were plans to perform a separate analysis for twin pregnancies. This analysis would have been used as a pilot for a future large study of twin pregnancies. However, recruiting twin pregnancies proved difficult. It is recognised that the recruitment of twin pregnancies in this study is inappropriate because twin pregnancies are more prone to preterm labour than singleton pregnancy [36-38]. This will be taken into consideration in designing further studies.

The mucosal surface of the female genital tract serves as a potential site of entry for a variety of bacterial and viral pathogens [24, 26, 38-41]. Most infections are confined to the lower genital tract. Consequently, a higher level of immunological activity is associated with this region [24, 38, 40-42].

In the cervix, leukocytes are sparse prior to the onset of labour [14, 40, 43]. There is increasing evidence that the process of cervical dilatation resembles an inflammatory response [40, 43]. Leucocytes migrate into cervical stroma and mucus during labour reaching a density $2-3$-fold higher than that found in late pregnancy [7, 43, 44]. This stromal infiltrate is composed principally of neutrophils and macrophages [43]. In contrast, others reported an increase in macrophage and neutrophil numbers in cervical stroma during late pregnancy, but no further changes during labour $[40,45]$. This discrepancy may relate to differences in cervical ripening at the time of the sample collection, but no clinical information on the state of the cervix was provided in any studies. This means that the identification of leukocyte phenotypes at the mucosal surface of the endocervix is integral to understanding the pathogenesis of genital infection and the role of protective immunity.

While all previous studies used manual counting to quantify cervical leukocytes, this is the first study that utilized flow cytometry to characterise cervical leukocytes in pregnant women. This study has characterised cervical leukocyte subpopulations in pregnant normal and high risk multiparous women.

The most prevalent cervical leukocyte was the macrophage. Macrophages and the rest of the leukocyte types were fewer in high risk patients than in normal pregnant controls, but this difference did not reach statistical significance. This could be due to the sample size. Or this could be due to the collection of the cervical samples very early in pregnancy. The influx of leukocytes is expected later in pregnancy [40, 45], or at the time of cervical ripening prior to labour [43]. The reason for collecting the cervical samples very early in pregnancy was to have enough time to treat patients with infection, manifested as high leukocyte readings, since early treatment of ascending infections may reduce preterm labour and birth by preventing the development of a minor infection into intrauterine infection [46-49]. Future studies designed to investigate leukocyte populations of the cervix in high risk patients should be planned between $18+0$ and $25+0$ weeks since this is likely to provide better information about the premature preparation of the cervix for delivery.

The cytobrush technique was successfully used to collect cervical samples. There are two major concerns regarding the use of the cytobrush to study immunological cells in the intraepithelial layer of the cervix. The first is to confirm that there are minimal levels of blood contamination that would distort and invalidate analysis. The second is to know whether cells are derived from the lamina propria as well as the intraepithelial layer compartment [50]. Even with blood contamination, flow cytometry differentiates between cervical and blood leukocytes because each has different cell volume and complexity, therefore blood leukocytes are represented in a different gate than the one used for the cervical leukocytes. Regarding the second concern, during cervical sampling, dislodgement of ectocervical cells is unavoidable. However, few leukocytes reside within the superficial layers of the ectocervix and this would not affect the results [24, 26, 38, 40, 42].

The use of the flow cytometer technique to characterise cervical leukocytes proved successful in general and beneficial especially in resolving any concerns about blood contamination of the cervical samples. If the cervical samples are contaminated by blood, the technique of the FACS analysis differentiates blood cells and cervical leukocytes. Blood cells can be separated in to two main gates, one represents the red blood cells (erythrocytes) since they are agranular and in different sizes which direct the gate to be in the lower end of the $\mathrm{Y}$-axis and distributed over the $\mathrm{X}$-axis. While leukocytes originating from blood contamination, are much smaller [50-52] and represented on the $\mathrm{X}$-axis far before cervical leukocytes, which almost represented at the same level as blood leukocytes on the Y-axis. This differentiation leads to the formation of three completely different gates one for the red blood cells, the other for leukocytes from blood contamination and the most important distinctive third is the gate of the cervical leukocytes, Figure 1.

Traditional methods to evaluate the cervix in pregnancy are limited and unsatisfactory. Attempts to screen women efficiently with risk-scoring systems or digital examination of the cervix, the standard method, suffers from large variation among examiners, and have revealed low sensitivities and low predictive values [53-55]. Vaginal ultrasonography produces good images and is well accepted by patients. There are no apparent risks associated with the examination [53-56]. In contrast, transvaginal ultrasonography is a reproducible method of examination during pregnancy. The length of the cervix is directly correlated with the duration of pregnancy: the shorter the cervix, the greater the likelihood of preterm delivery. This is mainly because uterine contractions, whether perceived by the woman or not, shorten the cervix [53-60]. 
3D ultrasound was first developed at Duke University in 1987 by Olaf von Ramm and Stephen Smith [61]. It was available for clinical research in the beginning then for clinical use in 1992. In 3D ultrasound scanning, instead of sound waves being sent straight down and reflected back, they are sent at different angels. The returning echoes processed by computer program which reconstruct three dimensional volume image, but no movement is shown [61, 62]. 3D ultrasonography has the potential to provide more accurate volume measurements than conventional 2D ultrasound [56-58, 61, 63]. 3D imaging combined with power Doppler became available for clinical use in 1995 and provided the potential to quantify power Doppler signals in a whole organ [56-59, 63, 64].

Results of this study showed a significant association between cervical length and preterm labour, but not the cervical volume. This could be due to the sample size or due to the difficulty of estimating cervical volume. Since one of the methodological difficulties when estimating cervical volume and vascularity using 3D ultrasound is defining landmarks when drawing the contours of the cervix [53, 56-59, 64-66].The delineation between the cervix and the lower uterine segment is particularly difficult, especially early in pregnancy and at mid-gestation when the lower uterine segment is thick and the cervix often curved. It may also be difficult to clearly separate the cervix from the surrounding vaginal tissue $[53,56-59,64,66]$.

Our hypothesis was that patients at high risk will have lower numbers of macrophages, and in turn less vascular cervix which would be seen as low readings on the power Doppler indices, but against our hypothesis, results of this study showed a significant inverse association between both vascular index and vascular flow index and preterm labour. On the other hand, flow index also increased in preterm labour patients than controls but this is not statistically significant. This means there is an increase in the vascularisation of the cervix in preterm labour patients. This result could be due to the small sample size or the difficulty in defining the landmarks when drawing the contours of the cervix which in turn affects the calculation of power Doppler indices. The last possible explanation is a premature remodeling of cervical architecture and this may include an element of preconceptional hypervascularity since all these women have previous history of preterm labour. The cervix of a patient who has had a previous history of preterm labour may have permanent changes to her cervix [40, 67-69]. Part of the ripening process is cytokine stimulation of an influx of macrophages and neutrophils which in turn not only produce more cytokines but also induce angiogenic activity with the result of newly formed microvessels which will allow more influx of the macrophages and neutrophils [67, 69]. Newly formed microvessels resolve soon after delivery but a small fraction remains as part of the normal structure of the cervix. In the next pregnancy these microvessels are represented as hypervascularity of the cervix [40, 67-71]. Accordingly, a preconceptional 3D ultrasound with power Doppler is needed to confirm or refute the presence of this phenomenon.

This is the first study to look at the correlation between macrophages, 3D ultrasound measurements and 3D ultrasound power Doppler indices. There was no correlation found between cervical macrophages and any of the cervical 3D ultrasound parameters measured. This could be due to the small sample size, the loss of some participants to the technical difficulty of presetting the ultrasound machine before each participant, or both. Also, participants joined this study early in pregnancy between $13+0$ and $17+0$ weeks. In the cervix, leukocytes are sparse prior to the onset of labour [14, 40, 43].

\section{Conclusion}

Cytobrush technique used successfully to collect cervical samples. Likewise, the use of flow cytometer technique to characterise cervical leukocytes proved successful in general and beneficial specially in resolving any concerns about blood contamination of the cervical samples. The most prevalent cervical leukocyte was macrophages. There was a significant association between cervical length and preterm labour, but not the cervical volume. Yet, there was no correlation found between cervical macrophages and any of the cervical 3D ultrasound parameters measured.

There is a real requirement for more research on cervical leukocyte population at reasonable time in pregnancy. Adding the 3D ultrasound element and power Doppler at the same time will provide voluble information about the cervical morphology.

\section{References}

[1]. Kiss H, Petricevic L, Husslein P. Prospective randomised controlled trial of an infection screening programme to reduce the rate of preterm delivery. BMJ. 2004;1136(10):1-5.

[2]. McGregor J, French J. Pathogenesis to treatment: preventing preterm birth mediated by infection. Infectious Diseases in Obstetrics and Gynaecology. 1997;5:106-14.

[3]. Kaaresen P, Ronning J, Ulvund S, Dahl L. A randomized, controlled trial of the effectiveness of an early-intervention program in reducing parenting stress after preterm birth. Pediatrics. 2006;118(1):9-19.

[4]. Carter J, Mulder R, Bartram A, Darlow B. Infants in a neonatal intensive care unit: parental response. Archives of Disease in Childhood. 2005;90:F109-F13.

[5]. Magill-Evans J, Harrison M. Parent-child interactions and development of toddlers born preterm. Western Journal of Nursery Research. 1999;21:292-307. 
[6]. Petrou S, Sach T, Davidson L. The long term costs of preterm birth and low birth weight: results of a systematic review. Child: Care, Health and Development. 2000;27(2):97-115.

[7]. Yost N, Cox S. Infection and Preterm Labour. Clinical Obstetrics and Gynaecology. 2000;43(4):759-67.

[8]. Chaim W, Mazor M, Leiberman J. The relationship between bacterial vaginosis and preterm birth. Archives of Gynecology and Obstetrics. 1997;259:51-8.

[9]. Cram L, Zapata M, Toy E, Baker B. Genitourinary infections and their association with preterm labor. American Family Physician. 2002;65(2):241-8.

[10]. Crowther C, Thomas N, Middleton P, Chua M, Esposito M. Treating periodontal disease for preventing preterm birth in pregnant women (Protocol). The Cochrane Database of Systematic Reviews. 2005 issue 4.

[11]. Hillier S, Nugent R, Eschenbach D, Krohn M, Gibbs R, Martin D, et al. Association between bacterial vaginosis and preterm delivery of a low birth weight infants. The New England Journal of Medicine. 1995;333(26):1737-42.

[12]. Klein L, Gibbs R. Use of microbial cultures and antibiotics in the prevention of infection-associated preterm birth. American Journal of Obstetrics and Gynecology. 2004;190:1493-502.

[13]. Reid G, Bocking A. The potential for probiotics to prevent bacterial vaginosis and preterm labour. American Journal of Obstetrics and Gynaecology. 2003;189(4):1202-8.

[14]. Romero R, Espinoza J, Chaiworapongsa T, Kalache K. Infection and prematurity and the role of preventive strategies. Seminaries in Neonatology. 2002;7:259-74.

[15]. Romero R, Chaiworapongsa T, Kuivaniemi H, Tromp G. Bacterial vaginosis, the inflammatory response and the risk of preterm birth: A role for genetic epidemiology in the prevention of preterm birth. American Journal of Obstetrics and Gynecology. 2004;190:1509-19.

[16]. Leitich H, Brunbauer M, Bodner-Adler B, Kaider A, Egarter C, Husslein P. Antibiotic treatment of bacterial vaginosis in pregnancy: A meta-analysis. American Journal of Obstetrics and Gynaecology. 2003; 188(3):752-8

[17]. Reid G, Bruce A, Fraser N, Heinemann C, Owen J, Henning B. Oral probiotics can resolve urogenital infections. FEMS Immunology and Medical Microbiology. 2001;30:49-52.

[18]. Reid G, Jass J, Sebulsky M, McCormick J. Potential Uses of Probiotics in Clinical Practice. Clinical Microbiology Reviews. 2003;16(4):658-72.

[19]. Kurki T. A survey of etiological mechanisms and therapy of preterm labor. Acta Obstetricia et Gynecologica Scandinavica. 1998;77:137-41.

[20]. Bernal A, Watson S, Phaneuf S, Europe-Finner G. Biochemistry and physiology of preterm labour and delivery. Bailliere's Clinical Obstetrics and Gynaecology 1993:523-52.

[21]. Goldenberg R, Hauth J, Andrews W. Intrauterine infection and preterm delivery. The New England Journal of Medicine. 2000;342(20):1500-7.

[22]. Goldenberg R, Culhane J. Prepregnancy health status and the risk of preterm delivery. Archives of Pediatric and Adolescent Medicine. 2005;159:89-90.

[23]. Goncalves L, Chaiworapongsa T, Romero R. Intrauterine Infection and Prematurity. Mental Retardation and Developmental Disabilities. 2002;8:3-13.

[24]. Hay P. Bacterial vaginosis and pregnancy. Infection and Pregnancy 2001:158-71.

[25]. Howe L, Wiggins R, Soothill P, Millar M, Horner P, Corfield A. Mucinase and sialidase activity of the vaginal micro flora: implications for the pathogenesis of preterm labour. International Journal of STD and AIDS. 1999;10:442-7.

[26]. Locksmith G, Duff P. Infection, antibiotics, and preterm delivery. Seminars in Perinatology. 2001;25(5):295-309.

[27]. Riggs M, Klebanoff M. Treatment of vaginal infections to prevent preterm birth: a meta-analysis. Clinical Obstetrics and Gynaecology. 2004;47(4):796-807.

[28]. Ganong W. Human reproduction. Review of medical physiology. 22nd ed: McGraw-Hill Companies 2005:519-601

[29]. Norman J. Cervical function and prematurity. Best Practice \& Research Clinical Obstetrics and Gynaecology. 2007:1-16

[30]. Vonderpool B. Preterm labor: diagnosis and treatment. American Family Physician. 1998;57(10):2457-70

[31]. Lamont R. Infection in preterm labour. Infection and Pregnancy 2001:305-17.

[32]. Wilks W, Wiggins R, Whiley A, Hennessy E, Warwick S, Porter H, et al. Identification and $\mathrm{H} 2 \mathrm{O} 2$ Production of Vaginal Lactobacilli from Pregnant Women at High Risk of Preterm Birth and Relation with Outcome. Journal of Clincal Microbiology. 2004;42(2):713-7.

[33]. Vause S, Johnston T. Management of preterm labour. Archives of Disease in Childhood. 2000;83:79-85

[34]. Othman M. Cervical Anatomy in Women at Risk of Preterm Labour. WebmedCentral OBSTETRICS AND GYNAECOLOGY 2013;4(4):WMC004206

[35]. Othman M. Cervical Immunology in Women at risk of preterm labour. WebmedCentral OBSTETRICS AND GYNAECOLOGY 2013;4(4):WMC004205

[36]. Cunningham F, MacDonald P, Gant N, Leveno K, Gilstrap L, Hankins G, et al. Preterm birth. In: Lange A, ed. Williams Obstetrics. 20th ed: McGraw-Hill Companies 1997:797-826.

[37]. Goldenberg R. The management of preterm labor. Obstetrics and Gynaecology. 2002;100(5):1020-1-37.

[38]. Haram K, Mortensen J, Wollen A. Preterm delivery: an overview. Acta Obstetricia et Gynecologica Scandinavica. 2003;82:687704.

[39]. Leitich H. Secondary predictors of preterm labour. BJOG. 2005;112(1):48-50.

[40]. Liggins G. Cervical ripening as an inflammatory reaction. The Cervix in Pregnancy and Labour. 3rd ed. Edinburgh: ChurchillLivingstone 1981:1-9.

[41]. MacLean A. Asymptomatic bacteriuria during pregnancy. Infection and Pregnancy 2001:85-95.

[42]. Marelli G, Papaleo E, Ferrari A. Lactobacilli for prevention of urogenital infections: a review. European Revision of Medical Pharmacological Science. 2004;8:87-95.

[43]. Osman I, Young A, Ledingham M, Thomson A, Jordan F, Greer I, et al. Leukocyte density and pro-inflammatory cytokine expression in human fetal membranes, decidua, cervix and myometrium before and during labour at term. Molecular Human Reproduction. 2003;9(1):41-5

[44]. Luo L, Ibaragi T, Maeda M, Nozawa M, Kasahara T, Sakai M, et al. Interleukin-8 levels and granulocyte counts in cervical mucus during pregnancy. American Journal of Reproductive Immunology. 2000;43:78-84

[45]. Bokstrom H, Brannstrom M, Alexandersson M, Norstrom A. Leukocyte subpopulations in the human uterine cervical stroma at early and term pregnancy. Human Reproduction. 1997;12(3):586-90.

[46]. Gibbs R, Esehenbaeh D. Use of antibiotics to prevent preterm birth. American Journal of Obstetrics and Gynecology. $1997 ; 177(2): 375-80$ 
[47]. Jacobsson B, Pernevi P, Chidekel L, Platz-Christensen J. Bacterial vaginosis in early pregnancy may predispose for pretermbirth and postpartum endometritis. Acta Obstetricia et Gynecologica Scandinavica. 2002;81:1006-10.

[48]. Lamont R. The prevention of preterm birth with the use of antibiotics. European Journal of Pediatrics. 1999;158(1):2-4.

[49]. Lamont R. Can antibiotics prevent preterm birth - the pro and con debate. British Journal of Obstetrics and Gynaecology. 2005;112(1):67-73.

[50]. Prakash M, Patterson S, Kapembwa M. Evaluation of the cervical cytobrush sampling technique for the preparation of CD45q mononuclear cells from the human cervix. Journal of Immunological Methods. 2001;258:37-46.

[51]. Hume D. The mononuclear phagocyte system. Current Opinion in Immunology. 2006;18:49-53.

[52]. Tacke F, Randolph G. Migratory fate and differentiation of blood monocyte subsets. Immunobiology. 2006;211:609-18.

[53]. Hoesli I, Surbek D, Tercanli S, Holzgreve W. Three dimensional volume measurement of the cervix during pregnancy compared to conventional 2D-sonography. International Journal of Gynecology \& Obstetrics. 1999;64:115-9.

[54]. Iams J, Goldenberg R, Meis P, Mercer B, Moawad A, Das A, et al. The length of the cervix and the risk of spontaneous premature delivery. The New England Journal of Medicine. 1996;334(9):567-72.

[55]. Iams J, Goldenberg R, Mercer B, Moawad A, Meis P, Das A, et al. The Preterm Prediction Study: Can low-risk women destined for spontaneous preterm birth be identified? American Journal of Obstetrics and Gynecology. 2001;184(4):652-5.

[56]. Rovas L, Sladkevicius P, Strobel E, Valentin L. Reference data representative of normal findings at three-dimensional power Doppler ultrasound examination of the cervix from 17 to 41 gestational weeks. Ultrasound in Obstetrics and Gynecology. 2006;28:761-7.

[57]. Rovas L, Sladkevicius P, Strobel E, Valentin L. Reference data representative of normal findings at two-dimensional and threedimensional gray-scale ultrasound examination of the cervix from 17 to 41 weeks' gestation. Ultrasound in Obstetrics and Gynecology. 2006;27:392-402.

[58]. Rozenberg P, Rafii A, Senat M, Dujardin A, Rapon J, Ville Y. Predictive value of two dimensional and three dimensional multiplaner ultrasound evaluation of the cervix in preterm labour. The Journal of Maternal-Fetal and Neonatal Medicine. $2003 ; 13: 237-41$.

[59]. Severi F, Bocchi C, Florio P, Picciolini E, D’aniello G, Petraglia F. Comparison of two-dimentsional and three-dimensional ultrasound in the assessment of the cervix to predict preterm delivery. Ultrasound in Medicine and Biology. 2003;29(9):1261-5.

[60]. Shennan A, Jones B. The cervix and prematurity: aetiology, prediction and prevention. Seminars in Fetal \& Neonatal Medicine 2004;9:471-9.

[61]. Ramm O, Smith S, inventors; 4694434, assignee. Three dimentional imaging system USA. 1987.

[62]. Michailidis G, Papageorgiou P, Economides D. Assessment of fetal anatomy in the first trimester using two and three dimentional ultrasound. British Journal of Radiology. 2002;75:215-9.

[63]. Rovas L, Sladkevicius P, Strobel E, Valentin L. Intraobserver and interobserver reproducibility of three-dimensional gray-scale and power Doppler ultrasound examinations of the cervix in pregnant women. Ultrasound Obstet Gynecol. 2005;26:132-7.

[64]. Rovas L, Sladkevicius P, Strobel E, SMET F, MOOR B, Valentin L. Three-dimensional ultrasound assessment of the cervix for predicting time to spontaneous onset of labor and time to delivery in prolonged pregnancy. Ultrasound in Obstetrics and Gynecology. 2006;28:306-11.

[65]. Saarela M, Mogensen G, Fonden R, Matto J, Mattila-Sandholm T. Probiotic bacteria: safety, functional and technological properties. Journal of Biotechnology. 2000;84:197-215.

[66]. Strauss A, Heer I, Fuchshuber S, Janssen U, Hillemanns P, Hepp H. Sonographic Cervical Volumetry in Higher Order Multiple Gestation. Fetal Diagnostic Therapy. 2001;16:346-53.

[67]. Dace D, Apte R. Effect of Senescence on Macrophage Polarization and Angiogenesis. Rejuvination Research. 2008;11(1):177-86.

[68]. Kelly R. Inflammatory mediators and cervical ripening. Journal of Reproductive Immunology. 2002;57:217-24.

[69]. Sunderk C, Steinbrink K, Goebeler TM, Bhardwaj R, Sorg C. Macrophages and angiogenesis. Journal of Leukocyte Biology. 1994;55:410-22.

[70]. Sennstrom M, Ekman G, Westergren-Thorsson G, Malmstrom A, Bystrom B, Endresen U, et al. Human cervical ripening, an inflammatory process mediated by cytokines. Molecular Human Reproduction. 2000;6(4):375-81.

[71]. Stjernholm-Vladic Y, Stygar D, Mansson C, Masironi B, Akerberg S, Wang H, et al. Factors involved in the inflammatory events of cervical ripening in humans. Reproductive Biology and Endocrinology. 2004;74(2):1-17. 